\title{
Erratum to: Double Rectangle Fascia Lata Frontalis Sling: A Rationale Approach for Ptosis
}

\author{
Pawan Agarwal ${ }^{1} \quad$ Dhananjaya Sharma ${ }^{2} \quad$ Vikesh Agrawal $^{3} \quad$ Swati Tiwari ${ }^{2} \quad$ Rajeev Kukrele $^{1}$
}

1Plastic Surgery Unit, Department of Surgery, NSCB Government Medical College, Jabalpur, Madhya Pradesh, India

${ }^{2}$ Department of Surgery NSCB Government Medical College, Jabalpur, Madhya Pradesh, India

${ }^{3}$ Medical College, Jabalpur, Madhya Pradesh, India

Indian J Plast Surg 2021;00:1-2

Publisher regrets to inform that the figures in the above-mentioned article published online on February 3, 2021 are incorrect. The doi of the article is $10.1055 / \mathrm{s}-0041-1723909$.

The correct figures are as below:

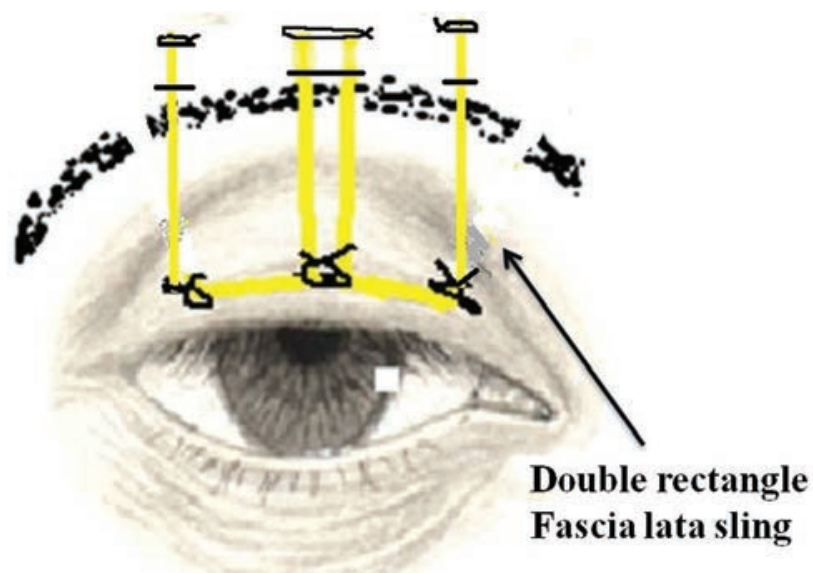

Fig. 1 Double rectangle (open superiorly) pattern of autologous fascia lata frontalis sling.

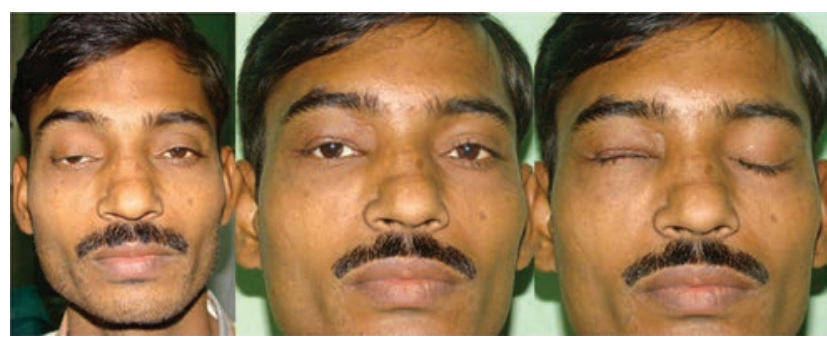

Fig. 3 Pre- and postoperative picture of right sided congenital ptosis correction with double rectangle fascia lata frontalis sling.
Address for correspondence Pawan Agarwal, MCh, DNB, FRCS, 292/293, Napier Town, Jabalpur, 482003 MP, India (e-mail: drpawanagarwal@yahoo.com).

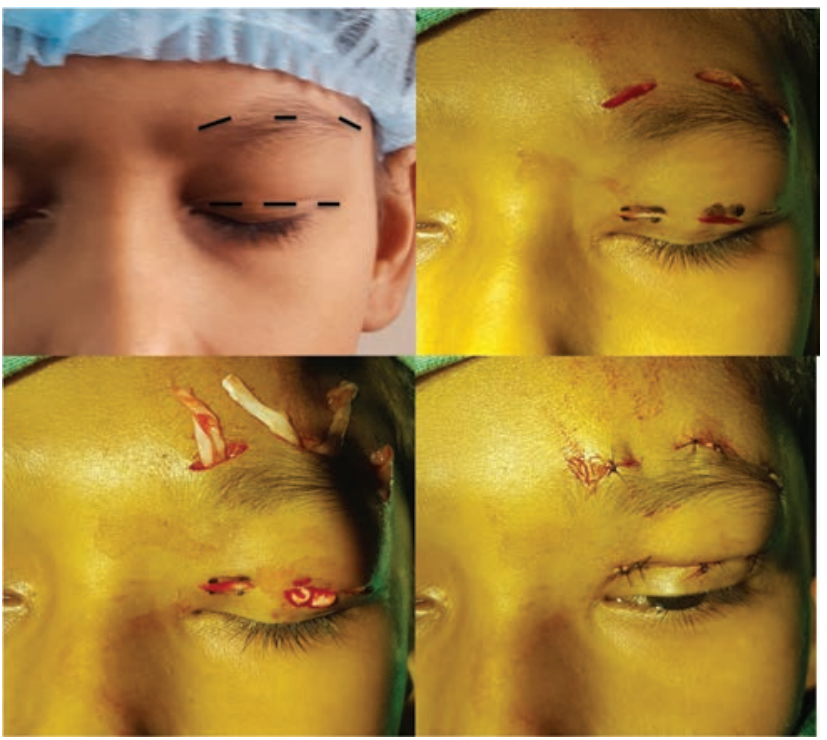

Fig. 2 Per-operative picture of ptosis correction with double rectangle fascia lata frontalis sling.

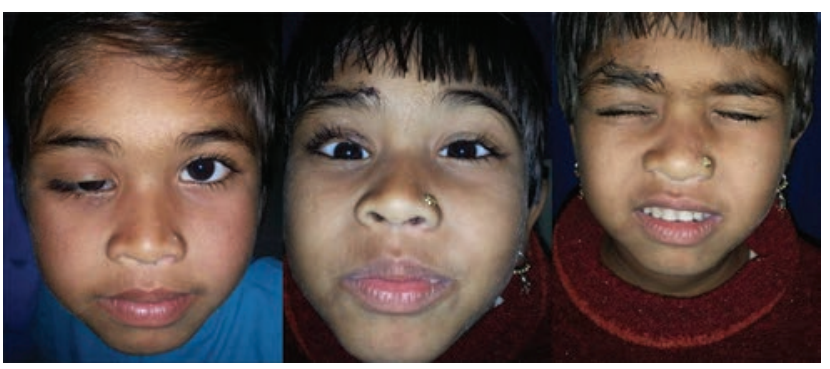

Fig. 4 Pre- and postoperative picture of right sided congenital ptosis correction with double rectangle fascia lata Frontalis sling.

(C)2021. Association of Plastic Surgeons of India

This is an open access article published by Thieme under the terms of the Creative Commons Attribution-NonDerivative-NonCommercial-License, permitting copying and reproduction so long as the original work is given appropriate credit. Contents may not be used for commercial purposes, or adapted, remixed, transformed or built upon. (https://creativecommons.org/licenses/by-nc-nd/4.0/).

Thieme Medical and Scientific Publishers Pvt. Ltd. A-12, 2nd Floor, Sector 2, Noida-201301 UP, India 


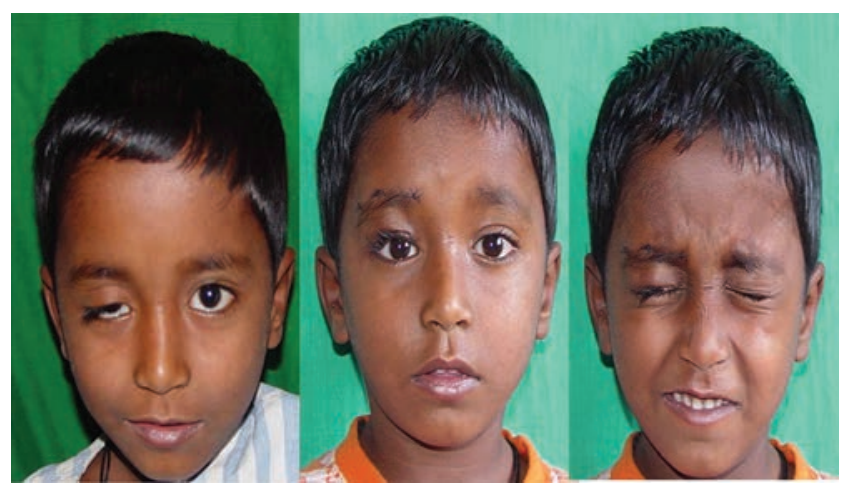

Fig. 5 Pre- and postoperative picture of right-sided congenital ptosis correction with double rectangle fascia lata frontalis sling.

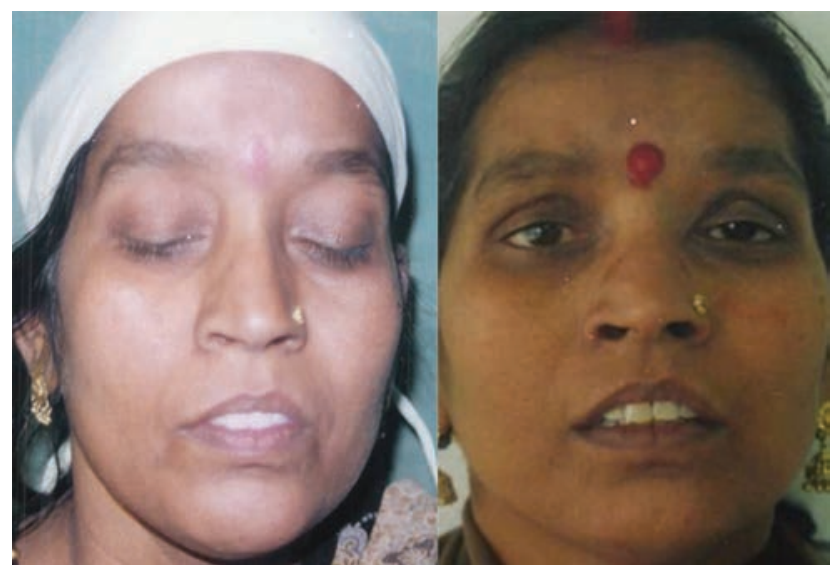

Fig. 6 Six months follow-up of bilateral acquired ptosis. 